\title{
Estudo da viabilidade de obtenção de isoladores elétricos a partir de resíduo de esmaltação
}

\section{(Study of the viability for obtaining electric insulators from enameling waste)}

\author{
F. J. P. Sousa ${ }^{1}$, W. F. das Neves ${ }^{2}$, O. E. Alarcon ${ }^{3}$ \\ ${ }^{1}$ Departamento de Engenharia Mecânica, Universidade Federal de Santa Catarina \\ Campus Universitário, Trindade, C.P. 476 \\ Florianópolis, SC 88040-900 \\ ${ }^{2}$ Cecrisa, Unidade industrial VI, Portinari, SC \\ ${ }^{3}$ Departamento de Engenharia de Materiais, Universidade Federal de Santa Catarina \\ Campus Universitário, Trindade, C.P. 476 \\ Florianópolis, SC 88040-900 \\ fabiodacivil@pg.materiais.ufsc.br
}

\begin{abstract}
Resumo
A gestão racional de resíduos industriais é um dos sérios problemas da sociedade atual. O presente trabalho tem por objetivo propor uma alternativa para o aproveitamento do resíduo de esmaltação da empresa Portinari, grupo Cecrisa S.A, por meio da utilização desse resíduo como principal componente em massas cerâmicas para obtenção de isoladores elétricos de distribuição secundária. Foram estudadas formulações contendo no mínimo $50 \%$ de resíduo e quantidades variáveis de alumina, feldspato potássico e de quartzo. O resíduo bruto foi primeiramente beneficiado e submetido às analises química, térmica e mineralógica para fins de caracterização. Adotou-se o processo de conformação plástica por torneamento para fabricação das amostras a verde, as quais foram secadas ao ar livre. As amostras obtidas foram submetidas a um ciclo térmico previamente indicado pela curva de gresificação do resíduo. Por fim, após a queima, os protótipos foram ensaiados quanto à rigidez dielétrica. Os resultados indicaram a compatibilidade técnica dos mesmos considerando o uso como isolador.
\end{abstract}

Palavras-chave: reaproveitamento, resíduos de esmaltação, resíduos industriais, isoladores elétricos.

\begin{abstract}
Wise management of industrial wastes is one of the most serious problems in today's society. The aim of the present work is to suggest an alternative way to reuse the enameling waste of Company Portinari Company, Cecrisa S.A, as major component in ceramic masses to the manufacturing of electric insulators. Formulations with variable amounts of alumina, potassic feldspar and quartz were used, all containing at least 50\% waste. The crude waste was firstly treated and then characterized by chemical and mineralogical analysis. The plastic molding process was used in order to produce the green samples, which were left to dry. The samples were submitted to a firing cycle previously indicated by a gresification curve for the waste. After that, the produced samples were submitted to a final test in order to estimate their dielectric rupture tension. The findings suggested a good technical compatibility of the waste considering its utilization as raw material for the production of electric insulators.

Keywords: Recycling, enameling waste, industrial wastes, electric insulators.
\end{abstract}

\section{INTRODUÇÃO}

Nas últimas décadas, em virtude da conscientização ambiental, da crescente competitividade e da intensa modernização das indústrias, a simples eliminação do resíduo não representa uma solução definitiva. Um bom exemplo de preocupação com o meio-ambiente é a opção por alternativas de reaproveitamento, visto que proporcionam um fim racional para o resíduo e, ao mesmo tempo, diminuem o consumo dos recursos naturais.

Este trabalho enfoca o resíduo da indústria Portinari Revestimentos Cerâmicos, unidade VI do grupo Cecrisa S.A.
Mensalmente são produzidas aproximadamente cinco toneladas de resíduos provenientes da limpeza de equipamentos e instalações, e das diversas etapas de produção, principalmente na esmaltação.

Devido ao grande número de atributos exigidos dos esmaltes, a composição dos mesmos é muitas vezes prejudicial ao meio ambiente e, portanto, os resíduos gerados na esmaltação não podem ser simplesmente descartados.

Segundo Rosa [1], a produção anual brasileira de revestimentos cerâmicos está em torno de 400 milhões de $\mathrm{m}^{2}$, consumindo cerca de 280 mil toneladas de esmaltes. Admitindose uma perda de $5 \%$ deste consumo, gera-se, anualmente, $14 \mathrm{mil}$ 
toneladas de resíduos considerados perigosos, com custo agregado, e provavelmente com algum potencial a ser explorado, em função das matérias-primas adotadas na composição dos esmaltes.

Atualmente, a maior parte desse resíduo é acondicionada em lagoas de decantação, e uma vez que seu acondicionamento correto é responsabilidade legal das próprias indústrias geradoras, o simples acúmulo do material gerado torna-se um problema econômico ao longo do tempo.

Assim, a idéia deste trabalho foi estudar o resíduo em questão, em termos de constituição e de propriedades, a fim de desenvolver uma alternativa de aproveitamento inovadora que venha a promover a substituição, ao menos parcial, do uso de matérias-primas virgens por um subproduto.

Como exemplo bem sucedido de uma solução inovadora pode-se citar o trabalho de Yalçin e Vahdettin [2], relatando o sucesso obtido com o uso de até $37 \%$ de resíduo proveniente da extração da bauxita (red mud), na composição de esmaltes para a aplicação em isoladores elétricos de porcelana.

Neste contexto, Souza Santos [3] e Schmidt [4] relataram que os próprios isoladores são obtidos a partir de caulim, argila, quartzo e feldspato. Uma vez que esses componentes podem perfeitamente estar presentes no resíduo estudado, decidiu-se analisar mais detalhadamente esta alternativa.

\section{Isoladores elétricos}

Um isolador elétrico é um dispositivo utilizado para garantir o isolamento de fios ou cabos energizados, com seus pontos de sustentação adjacentes. Exige-se, portanto, que o isolador possua uma grande capacidade de se opor à passagem de corrente elétrica, além de elevada resistência mecânica [5].

Existem várias maneiras de se identificar um material isolante, tais como o critério das cargas livres, ou das bandas de energia. No entanto, devido à complexidade do assunto frente aos poucos resultados experimentais obtidos, esta revisão se limitará a uma abordagem superficial das propriedades elétricas, incluindo apenas resistividade e rigidez dielétrica.

A resistividade pode ser definida pelo grau de oposição que o material oferece à passagem de corrente elétrica, enquanto rigidez dielétrica, segundo Saraiva [5], é a propriedade do material se opor à descarga elétrica através de sua estrutura. A diferença entre resistividade e rigidez dielétrica é que na primeira o material permanece intacto, pois há apenas uma simples passagem de uma corrente elétrica, enquanto na segunda há uma descarga elétrica que prejudica a integridade estrutural da peça.

Em se tratando de componentes, isto é, corpos geometricamente definidos, o grau de oposição à passagem elétrica é a resistência do componente, enquanto a ocorrência de descarga elétrica caracteriza a ruptura dielétrica do mesmo.

Assim, de acordo com o formato um isolador pode apresentar ruptura dielétrica sob tensões mais elevadas que outro de mesmo material. As exigências quanto à forma e às propriedades dos isoladores a serem usados no sistema de distribuição de energia elétrica no estado de Santa Catarina são especificadas em um manual especial da Celesc [6], sob título "Isoladores de Porcelana", e sob o código E-313.0011, o qual prevalece sobre o recomendado pelas normas técnicas da ABNT.

Além da forma, os isoladores são classificados de acordo com tensão nominal que devem suportar e conforme a distância que a corrente elétrica deve percorrer através do material. Esta distância é definida no referido manual como distância de perfuração.

Isoladores de baixa tensão trabalham com tensões nominais inferiores a $1000 \mathrm{~V}$, possuindo um ou dois leitos vitrificados para acomodação de cabos condutores, e distância de perfuração menor que metade da distância a ser percorrida pela corrente elétrica ao longo da superfície do isolador.

O formato dos isoladores elétricos é definido na etapa de conformação, que se dá por moldagem plástica com o uso de torneamento, por se tratar de peças radialmente simétricas. A Fig. 1 mostra o torno usado para a conformação dos isoladores, juntamente com a chapelona, ferramenta usada para a definição do perfil.
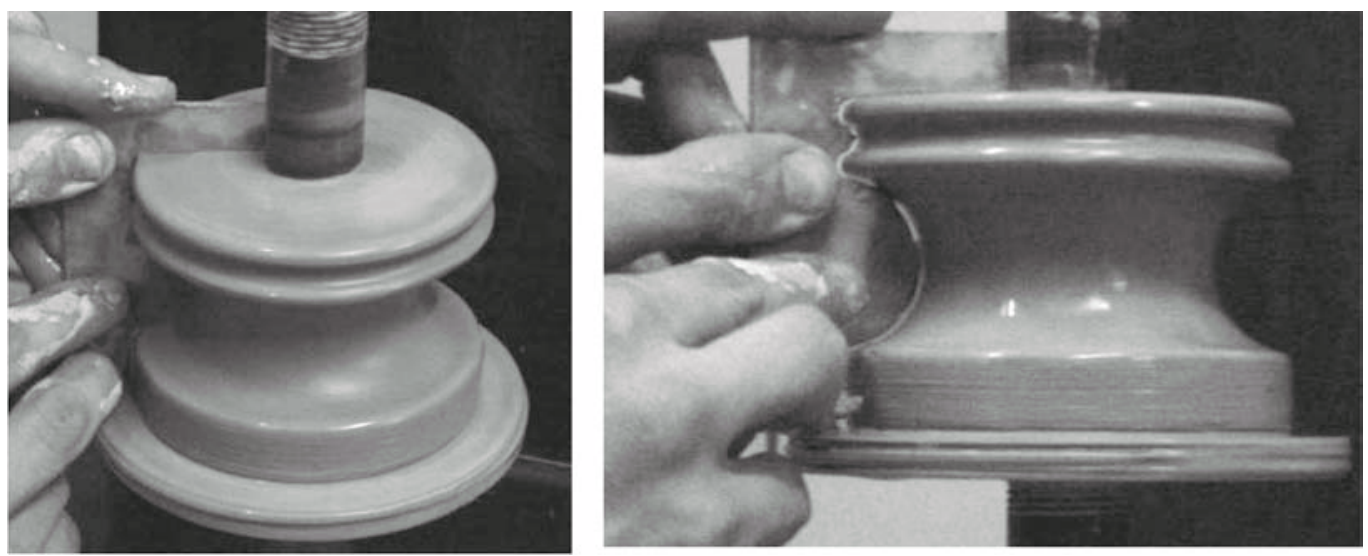

Figura 1: Torno e chapelona em acrílico.

[Figure 1: Jigger and acrylic mold for insulator jiggering.] 
Uma importante etapa produtiva é a secagem das peças após a conformação.

Em termos de tecnologia cerâmica, a secagem consiste na remoção do líquido, geralmente água, que anteriormente conferia a trabalhabilidade necessária à peça [7]. Trata-se de uma etapa decisiva, na qual a retração volumétrica que ocorre simultaneamente à perda de água requer uma série de cuidados para evitar que ainda nesta etapa apareçam trincas irreversíveis nas peças moldadas.

Assim, ao se elaborar uma massa plástica para fins de conformação a úmido, deve-se levar em conta a retração esperada ao final da secagem. Uma grande retração requer cuidados especiais na secagem, o que pode acarretar um sério gargalo produtivo. Maiores detalhes sobre a secagem a plasticidade de massas cerâmicas podem ser encontradas na literatura [8].

\section{MATERIAIS E MÉTODOS}

Os procedimentos realizados neste trabalho subdividemse nas etapas de beneficiamento do resíduo bruto, caracterização do resíduo beneficiado, confecção das amostras e estimativa de desempenho do produto final.

O beneficiamento consistiu basicamente na desagregação manual de torrões e na retirada de materiais orgânicos e de objetos considerados estranhos ao resíduo, tais como pregos e pedaços de concreto.

Para uma melhor manipulação e homogeneização durante o beneficiamento, $6 \mathrm{~kg}$ de resíduo foram diluídos em cerca de $10 \mathrm{~L}$ de água, e posteriormente submetidos a um peneiramento grosso, em malha de $2 \mathrm{~mm}$. Do resíduo beneficiado, retirouse cerca de $1 \mathrm{~kg}$ exclusivamente para fins de caracterização. O material restante foi utilizado na obtenção de isoladores elétricos. A Fig. 2 resume os procedimentos adotados.
As análises química e térmica foram realizadas pelo Centro de Tecnologia em Cerâmica - CTC. O material destinado à caracterização foi moído em almofariz, enquanto que a moagem do material para confecção dos protótipos foi feita em moinho de bolas. Neste caso, além da melhora na homogeneização do resíduo beneficiado, a moagem visa promover um aumento da plasticidade do mesmo em função da diminuição do tamanho de partículas do material.

A cada moagem, $2 \mathrm{~kg}$ de material beneficiado eram colocados em moinhos de bolas com 5 L de capacidade, juntamente com 80 esferas de alumina grandes $(29 \mathrm{~mm}$ de diâmetro) e 160 pequenas $(19 \mathrm{~mm})$, e $2,5 \mathrm{~L}$ de água. Usou-se rotação de $28 \mathrm{rpm}$, e tempo de moagem de $24 \mathrm{~h}$.

Embora a composição e a quantidade do resíduo varie a cada adequação da empresa ao mercado consumidor, admitiuse que estas variações não causem grandes modificações na composição do resíduo final. Isto devido ao considerável volume de resíduo em geração e em estoque.

A amostra de material enviada ao CTC foi analisada por meio de fluorescência de raios $\mathrm{X}$, em equipamento Philips, modelo PW 2400. Esta técnica detecta e quantifica a presença de até $10 \mathrm{ppm}$ dos elementos químicos com $Z>5$.

Para a análise mineralógica usou-se a técnica de difração de raios $\mathrm{X}$, tomando-se a amostra de resíduo na forma de pó, com diâmetro máximo de partícula $45 \mu \mathrm{m}$. Adotou-se inicialmente a faixa angular de varredura de $5^{\circ}$ a $70^{\circ}$ para $2 \theta$, passo de $0,05^{\circ}$ e tempo de coleta $1 \mathrm{~s}$. As amostras foram orientadas em água.

Para efeito de comparação, foi realizada também a caracterização de um isolador comercial similar. Neste caso, a faixa de varredura e o tempo de coleta em cada posição angular foram de $5^{\circ}$ a $80^{\circ}$ e $2 \mathrm{~s}$, respectivamente.

A interpretação dos resultados foi feita no programa PCIDENTIFY $^{\circledR}$, versão 1.0 da Philips, e por um resultado de

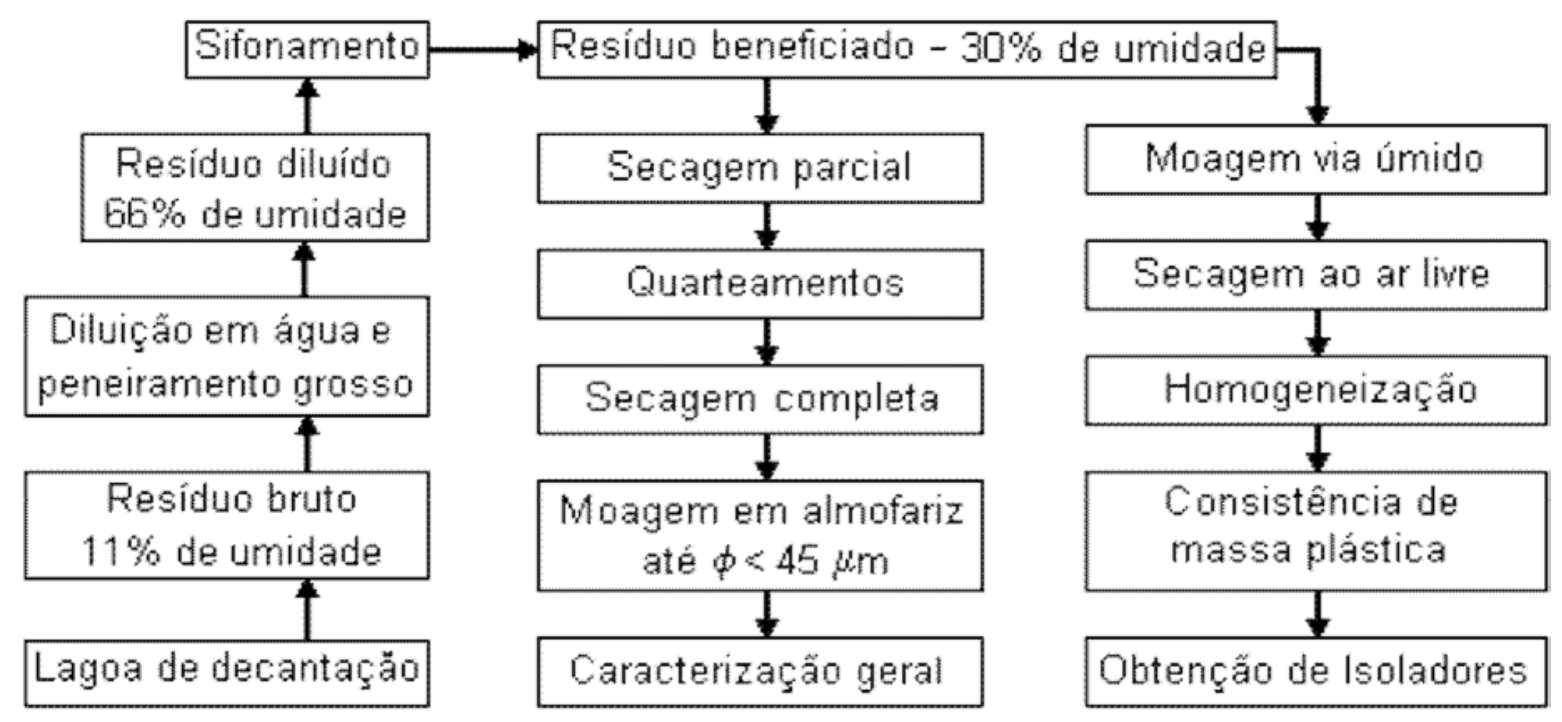

Figura 2: Separação do resíduo.

[Figure 2: Diagram of waste separation.] 
análise química por fluorescência, o que permitiu uma grande restrição do número de possíveis elementos na amostra, além da identificação de fases realmente significativas em termos de composição.

Adicionalmente, visando-se obter a temperatura de patamar mais adequada para o processamento térmico dos isoladores, elaborou-se uma curva de gresificação do resíduo. Para isto usou-se um forno gradiente Nanneti, taxa de aquecimento de $15{ }^{\circ} \mathrm{C} / \mathrm{min}$. e tempo de patamar de $15 \mathrm{~min}$. A curva foi traçada com base em 10 diferentes temperaturas de patamar, obtidas de modo alternado em dois ciclos de queimas. Os resultados de retração linear foram complementados por ensaios de absorção de água, feitos conforme a NBR 13818 [9]. Cada resultado representa a média de dois corpos-de-prova.

\section{Obtenção de isoladores elétricos}

Considerou-se neste trabalho apenas os isoladores de baixa tensão, tipo olhal e roldana em virtude do menor controle requerido no processo de fabricação, de especificações técnicas mais tolerantes, e do menor rigor estabelecido para os ensaios de recebimento das Centrais elétricas de Santa Catarina CELESC, grande consumidora desses produtos. Contudo, as especificações constantes no item 5.2 do manual da CELESC [6], sobre as exigências para a aceitação de isoladores de porcelana, aplicam-se apenas aos isoladores fabricados a partir de materiais já conhecidos. Para isoladores com tensões de serviço inferiores a $1 \mathrm{kV}$, como os usados na rede de distribuição secundária, desenvolvidos a partir de outros materiais, o mesmo item recomenda consultar diretamente a CELESC. Esta consulta não foi agendada durante este trabalho em virtude da grande variabilidade nas dimensões das peças e da pequena escala de produção atingida até o presente momento.

Visando maior consumo de resíduo, e menor preço final do isolador, considerou-se primeiramente o uso de resíduo sem a adição de qualquer matéria-prima comercial. Contudo, devido ao insucesso durante o processo de secagem, tornouse necessária a adição de diferentes quantidades de alumina, argila, quartzo e feldspato potássico. A primeira matéria-prima comercial foi fornecida pela empresa Alcoa, enquanto as demais, pela Colorminas. A opção por essas matérias-primas foi sugerida pela literatura. NORTON [10] ainda cita quantias aproximadas de $28 \%, 20,32 \%$ e $20 \%$ para as matérias-primas: quartzo, feldspato, caulim e argila, respectivamente.

A Tabela I apresenta a composição das formulações

Tabela I - Formulações submetidas ao ensaio de rigidez dielétrica.

[Table I - Insulator compositions submitted to dielectric strength tests.]

\begin{tabular}{cccccc}
\hline Amostra & Resíduo & Argila & Feldspato & Quartzo & Alumina \\
\hline 1 & 50 & 20 & 20 & 10 & - \\
\hline 2 & 50 & - & 17,5 & 22,5 & 10 \\
\hline 3 & 50 & - & 17,5 & 22,5 & 10 \\
\hline
\end{tabular}

adotadas. O percentual de cada material foi calculado com base na diferença entre a composição química do resíduo e a do isolador comercial padrão, e mantendo-se o percentual do resíduo em 50\%. Uma vantagem do uso de outras matériasprimas é a diminuição do efeito das variações de composição do resíduo no produto final.

A opção por fabricar isoladores do tipo roldana se deve à simetria radial dos mesmos, sendo facilmente conformados por torneamento com auxílio de uma chapelona, e contando com os equipamentos disponíveis no Laboratório de Engenharia Mecânica da UFSC - LabMat. A chapelona foi obtida a partir de uma placa de acrílico cortada por um equipamento a laser desenvolvido no próprio LabMat. Tomouse por referência o desenho especificado pelo manual da CELESC.

Depois de torneadas, as peças foram deixadas ao ar livre até adquirirem o aspecto seco. Em seguida, os isoladores a verde foram colocados em um formo elétrico residencial Fisher, e aquecidos a $110^{\circ} \mathrm{C}$ até apresentarem massa constante.

Após a secagem, as peças foram queimadas separadamente em um forno elétrico de ciclo rápido Schaly, sem a aplicação de qualquer camada de esmalte. Devido à grande quantidade de quartzo livre presente, adotou-se uma pequena taxa de aquecimento nas proximidades da temperatura de inversão do quartzo a $573{ }^{\circ} \mathrm{C}$. As amostras foram mantidas no interior do forno até a temperatura ambiente, resfriando-se naturalmente. O ciclo térmico programado é detalhado na Fig. 3.

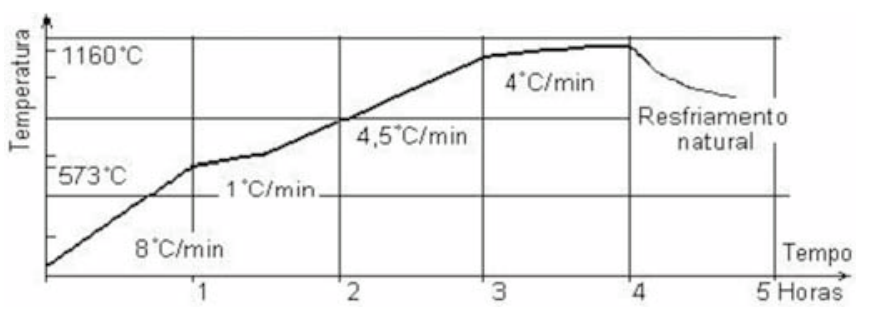

Figura 3: Curva programada para queima dos isoladores. [Figure 3: Cycle adopted for firing the insulators.]

Com base na curva de gresificação obtida para o resíduo, usou-se temperatura de patamar de $1160^{\circ} \mathrm{C}$ e tempo de patamar de $15 \mathrm{~min}$. Contudo, o ciclo de queima efetivo apresentou taxas de aquecimento ligeiramente menores, resultando em ciclos com duração de até $5 \mathrm{~h}$. Os efeitos dessa perturbação foram desconsiderados devido ao tempo de permanência em altas temperaturas, acima de $1000^{\circ} \mathrm{C}$, ter sido praticamente o mesmo para todas as amostras.

\section{Medidas de rigidez dielétrica}

Os ensaios de rigidez dielétrica foram realizados nas instalações da Eletrosul S.A. Foram ensaiadas as três primeiras amostras de isoladores produzidas sem quaisquer defeitos aparentes. Simulando-se a condição de uso observada nas redes de distribuição, as amostras foram arranjadas de modo a isolar um cabo envolvente energizado de um terminal neutro colocado no interior da mesma. A Fig. 4 esquematiza este ensaio. 

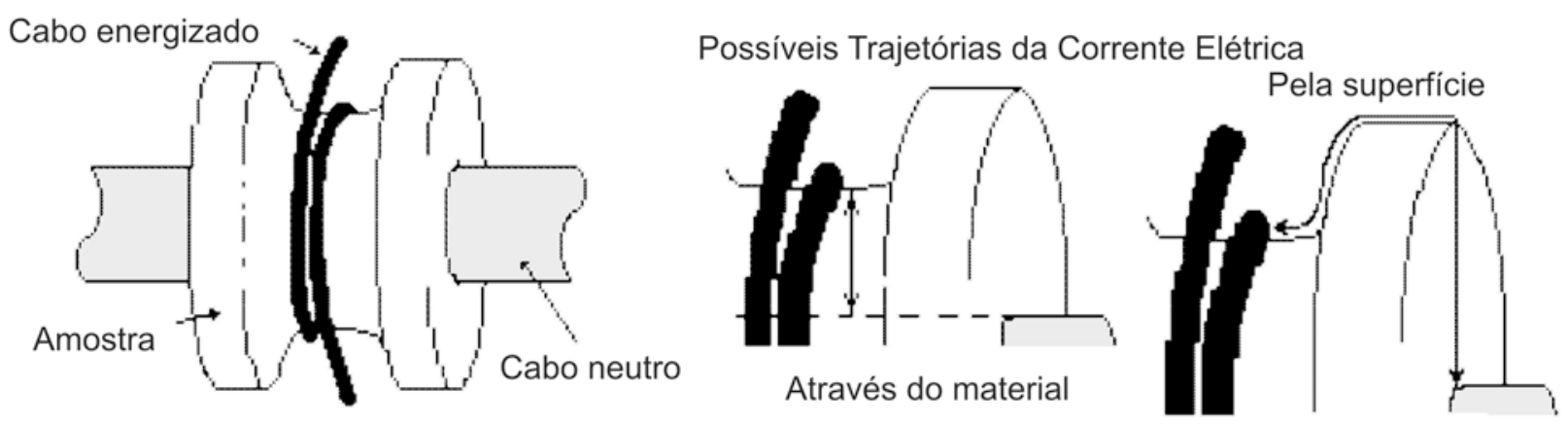

Figura 4: Esquema de ensaio para medição da rigidez dielétrica.

[Figure 4: Illustration of the dielectric strength tests.]

A tensão aplicada foi continuamente aumentada até ocorrer a ruptura dielétrica do material, por uma entre as duas trajetórias possíveis ilustradas acima.

\section{RESULTADOS E DISCUSSÃO}

Os resultados obtidos compreendem uma caracterização geral do resíduo e, por fim, resultados quanto ao uso do mesmo em massa para isoladores. A Fig. 5 apresenta as curvas de retração e de absorção de água do resíduo.

O comportamento de ambas as curvas é governado pela porosidade da peça. A acentuada retração linear e diminuição da absorção de água a partir de $1050^{\circ} \mathrm{C}$ devem-se ao início da formação de fase líquida. A temperatura de queima mais indicada situa-se entre $1150^{\circ} \mathrm{Ce} 1175^{\circ} \mathrm{C}$, devido aos melhores índices de absorção de água e retração linear obtidos.

Nas colunas R e I C da Tabela II encontram-se os resultados quantitativos da composição química obtidos por análise de fluorescência de raios X. Os resultados de uma análise semelhante da literatura [1], encontram-se na coluna L

As largas faixas de concentração citadas na literatura se devem à grande variabilidade de composição química normalmente apresentada por esse tipo de resíduo. Para a

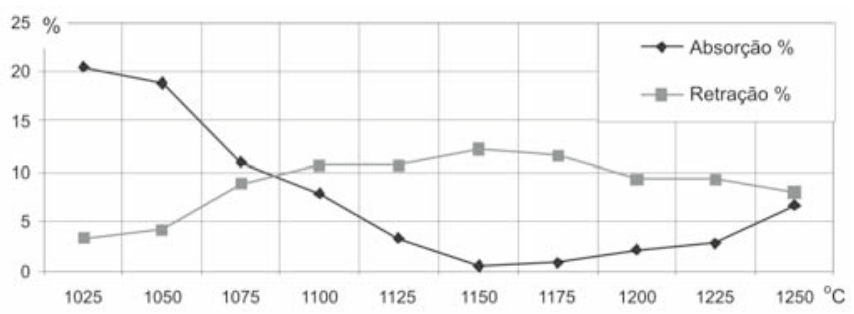

Figura 5: Curva de gresificação do resíduo.

[Figure 5: Vitrification curve of wastes.]

grande maioria dos óxidos, os resultados da análise química estão de acordo com a literatura. $\mathrm{O}$ elemento boro não poderia ser detectado pelo seu pequeno peso atômico $(Z=3)$. Por outro lado, a ausência de chumbo e bário sugere uma preocupação das grandes indústrias quanto ao uso de matérias-primas tóxicas. Não foi realizada a análise química do resíduo após a queima. Contudo, observa-se que há basicamente os mesmos elementos químicos, e cabe lembrar ainda que haveria uma maior aproximação entre as composições químicas ao se recalcular os percentuais desconsiderando a perda ao fogo.

Os difratogramas obtidos para o resíduo nas condições beneficiado e queimado a $1150^{\circ} \mathrm{C}$ são apresentados nas Figs.

Tabela II - Resultados das análises químicas.

[Table II - Results of chemical analysis.]

\begin{tabular}{cccccccc}
\hline Óxidos & $\mathrm{R}(\%)$ & $\mathrm{L}(\%)$ & $\mathrm{I} \mathrm{C}(\%)$ & Óxidos & $\mathrm{R}(\%)$ & $\mathrm{L}(\%)$ & $\mathrm{I} \mathrm{C}(\%)$ \\
\hline $\mathrm{SiO}_{2}$ & 56,95 & $40,0-60$ & 73,13 & $\mathrm{TiO}_{2}$ & 0,60 & $0,0-0,7$ & 0,33 \\
\hline $\mathrm{Al}_{2} \mathrm{O}_{3}$ & 15,05 & $5,0-15$ & 19,78 & $\mathrm{MgO}$ & 1,79 & $0,5-3,0$ & 0,79 \\
\hline $\mathrm{B}_{2} \mathrm{O}_{3}$ & - & $0,0-10$ & - & $\mathrm{P}_{2} \mathrm{O}_{5}$ & 0,19 & - & 0,15 \\
\hline $\mathrm{Fe}_{2} \mathrm{O}_{3}$ & 1,89 & $0,1-5$ & 0,55 & $\mathrm{ZnO}$ & 3,32 & $1,0-8,0$ & - \\
\hline $\mathrm{CaO}$ & 4,89 & $5,0-15$ & 0,11 & $\mathrm{PbO}$ & - & $0,1-15,0$ & - \\
\hline $\mathrm{Na}_{2} \mathrm{O}$ & 1,03 & $0,5-3$ & 0,89 & $\mathrm{BaO}$ & - & $0,1-0,8$ & - \\
\hline $\mathrm{K}_{2} \mathrm{O}$ & 2,22 & $0,5-3$ & 3,98 & $\mathrm{ZrO}_{2}$ & 4,01 & $1,0-15$, & - \\
\hline $\mathrm{MnO}$ & 0,03 & - & 0,01 & $\mathrm{P.} \mathrm{fogo}$ & 8,03 & $1,0-12,0$ & 0,28 \\
\hline
\end{tabular}




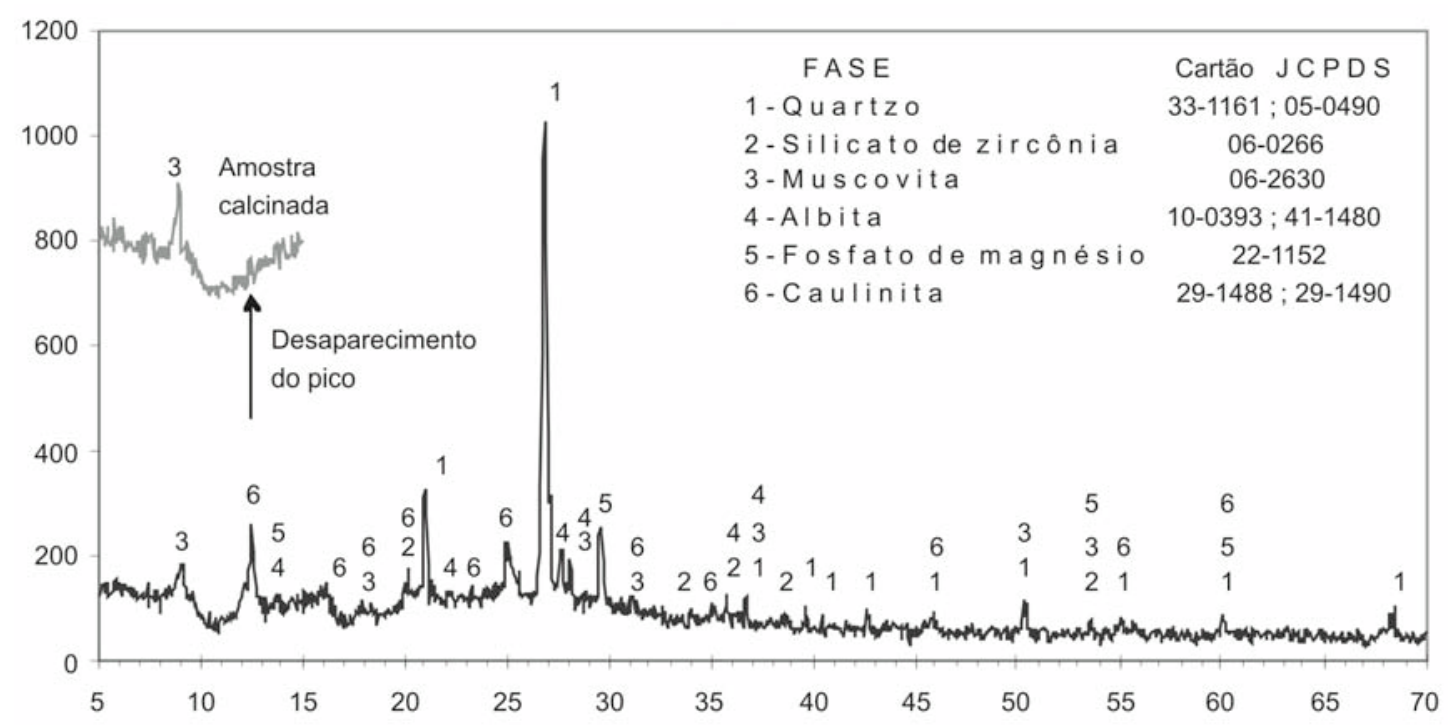

Figura 6: Difratograma de raios $\mathrm{X}$ do resíduo beneficiado.

[Figure 6: X-ray diffraction pattern of the treated waste.]

6 e 7 , respectivamente. Como complemento, foi ensaiada uma amostra de resíduo, apenas na faixa entre $5^{\circ}$ e $15^{\circ}$, orientada e calcinada a $550{ }^{\circ} \mathrm{C}$, unicamente para se confirmar a presença de caulinita por meio do desaparecimento do pico próximo a doze graus [3].

A presença de quartzo $\left(\mathrm{SiO}_{2}\right)$ e caulinita $\left(\mathrm{Al}_{2} \mathrm{Si}_{2} \mathrm{O}_{5}(\mathrm{OH})_{4}\right)$ em resíduos de esmaltação é citada por Rosa [1]. No entanto, além destas fases, o autor comenta a presença de calcita, cujos picos não foram observados no resíduo da Portinari. O silicato de zircônio $\left(\mathrm{ZrSiO}_{4}\right)$ é geralmente utilizado em fritas [11]. As demais fases presentes, muscovita $\left(\mathrm{KAl}_{2}\left(\mathrm{Si}_{3} \mathrm{Al}\right) \mathrm{O}_{10}(\mathrm{OH})_{2}\right)$, fosfato de magnésio $\left(\mathrm{Mg}_{2} \mathrm{P}_{2} \mathrm{O}_{7}\right)$ e albita $\left(\mathrm{Na}\left(\mathrm{Si}_{3} \mathrm{Al}\right) \mathrm{O}_{8}\right)$ são provavelmente inerentes ao processo produtivo.

Nota-se que as fases cristalinas quartzo, silicato de zircônio e albita continuaram presentes no resíduo após a queima. A ocorrência de um halo indica a fusão de algum material seguida pela formação de fase vítrea, o que é concordante com o comportamento apresentado na curva de gresificação do resíduo.

Além da formação de anortita $\left((\mathrm{Ca}, \mathrm{Na})(\mathrm{Si}, \mathrm{Al})_{4} \mathrm{O}_{8}\right)$, verificouse que o elemento fósforo passou a se ligar na forma do seu óxido mais estável $\left(\mathrm{P}_{2} \mathrm{O}_{5}\right)$. Este óxido é classificado como formador de rede [12], isto é, tem grande tendência a formar vidro, e o fato dos picos evidenciarem fase cristalina deve-se provavelmente à lenta condição de resfriamento, uma vez que as amostras foram mantidas dentro do forno, esfriado naturalmente.

O processo de conformação das amostras pode ser visto na Fig. 1. A Fig. 8a mostra a secagem de várias amostras a verde, enquanto a Fig. 8 b exemplifica uma trinca de secagem.

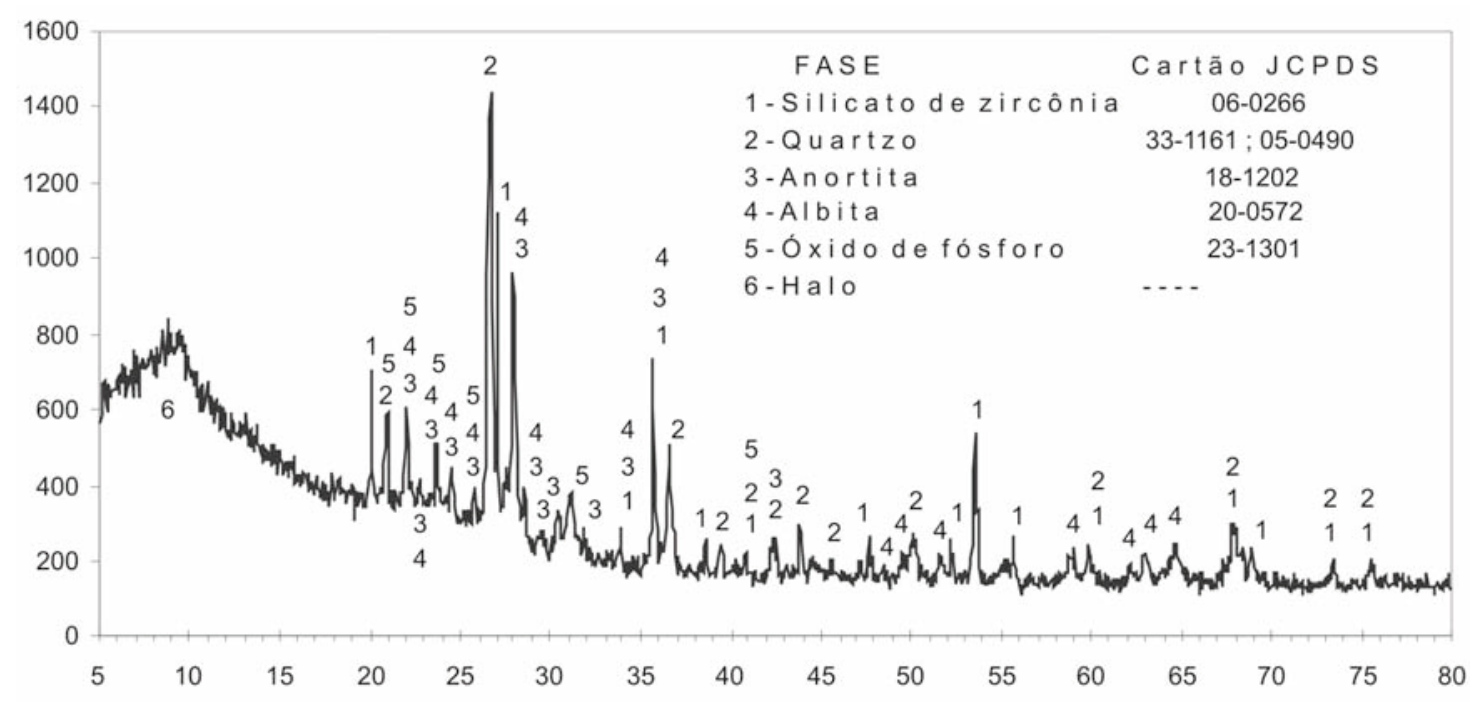

Figura 7: Difratograma de raios $\mathrm{X}$ do resíduo queimado a $1150{ }^{\circ} \mathrm{C}$.

[Figure 7: X-ray diffraction pattern of the waste fired at $1500^{\circ} \mathrm{C}$.] 


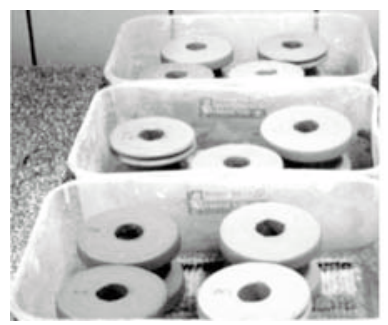

Figura 8: (a) Secagem das amostras; (b) trinca de secagem. [Figure 8: (a) Drying process of samples; (b) cracks due to the drying process.]
O processo de torneamento provoca uma orientação preferencial das partículas superficiais da peça moldada. Este efeito é considerado benéfico, visto que confere um aspecto mais liso à peça.

O difratograma obtido para o isolador comercial é apresentado na Fig. 9. Constata-se a presença de quartzo, mulita $\left(\mathrm{Al}_{6} \mathrm{Si}_{2} \mathrm{O}_{13}\right)$ e de fase vítrea.

A Fig. 10 compara os difratogramas relativos ao resíduo e ao isolador comercial. Nota-se uma boa semelhança entre os mesmos, inclusive com relação à fase vítrea.

Da esquerda para a direita, a Fig. 11 apresenta o exemplar

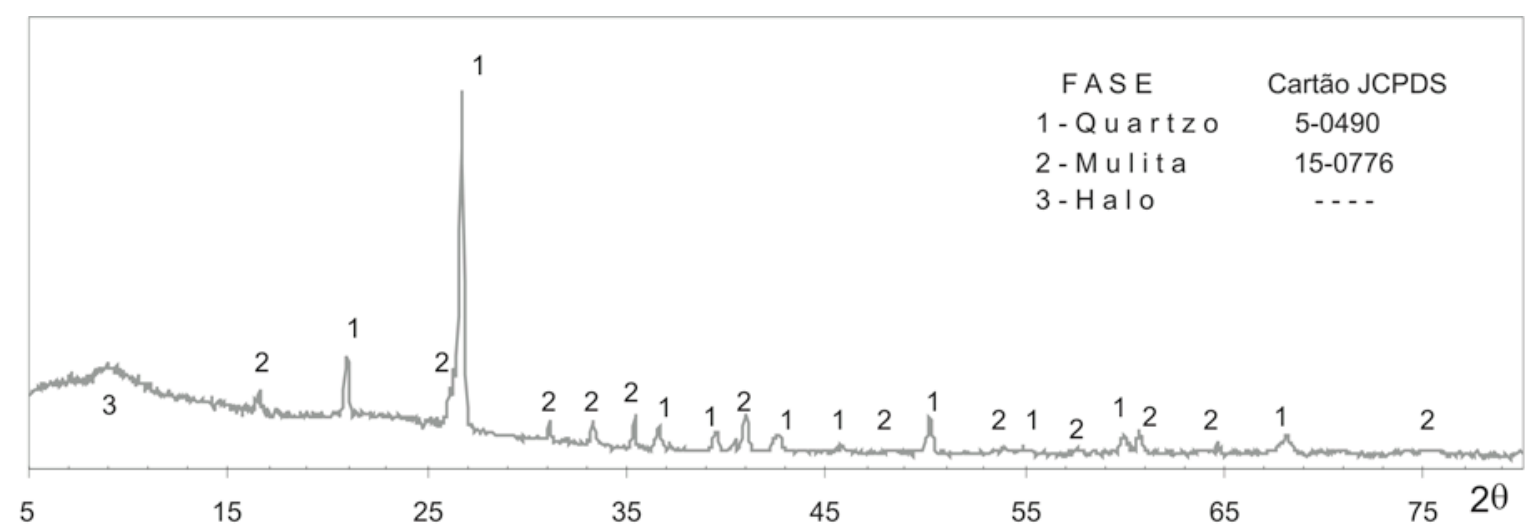

Figura 9: Fases presentes no isolador comercial. [Figure 9: Phases in commercial insulator.]

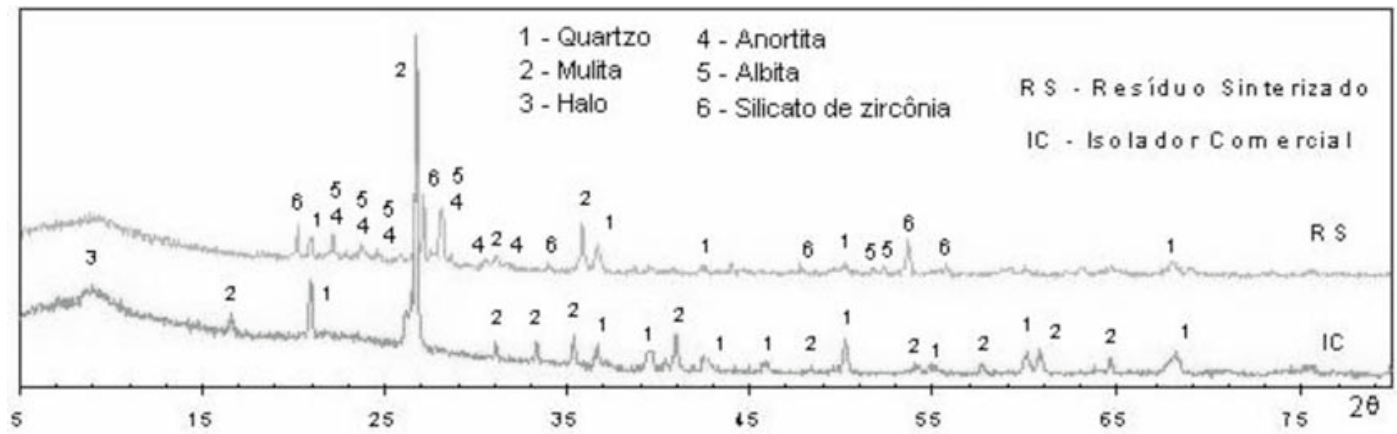

Figura 10: Difratogramas de raios $\mathrm{X}$ do resíduo sinterizado e de um isolador comercial. [Figure 10: X-ray diffraction patterns of sintered waste and commercial insulator.]

Tabela III - Rigidez dielétrica obtida para cada formulação. [Table III - Dielectric strength of each formulation.]

\begin{tabular}{ccccccc}
\hline Amostra & $\begin{array}{c}\text { Rigidez } \\
\text { Dielétrica }(\mathrm{kV})\end{array}$ & Resíduo & Argila & Feldspato Quartzo & Alumina \\
\hline 1 & 25,8 & 50 & 20 & 20 & 10 & - \\
\hline 2 & 26,3 & 50 & - & 17,5 & 22,5 & 10 \\
\hline 3 & 26,3 & 50 & - & 17,5 & 22,5 & 10 \\
\hline
\end{tabular}




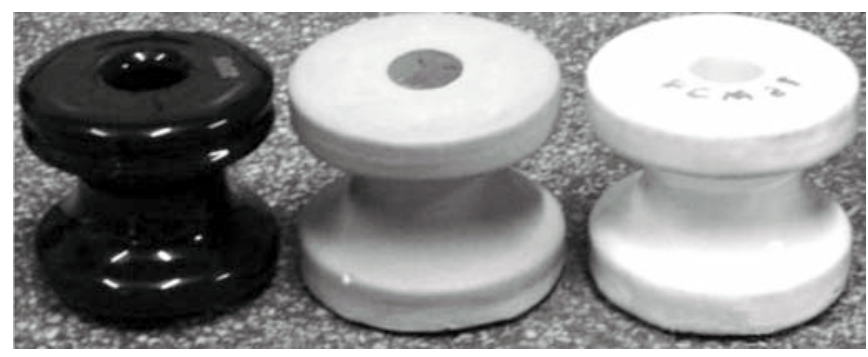

Figura 11: Isoladores obtidos a partir do resíduo. [Figure 11: Insulators obtained by using waste.]

de isolador comercial, e dois protótipos obtidos à partir de resíduo de esmaltação, sendo o último, com a inscrição PGMat, esmaltado apenas para fins de ilustração, com o uso de esmalte fornecido pela Portinari. A queima das amostras deu-se a $1160^{\circ} \mathrm{C}$.

\section{Medidas de rigidez dielétrica}

Os resultados dos ensaios de rigidez dielétrica encontramse na Tabela III. Vale lembrar que o acabamento superficial foi conferido diretamente pelo torneamento, uma vez que as amostras ensaiadas não estavam esmaltadas.

A ruptura dielétrica ocorreu pela superfície do material, de maneira que a aplicação de um esmalte adequado nas amostras certamente implicaria em maiores valores de rigidez dielétrica.

Apesar de serem necessários estudos mais detalhados, incluindo uma caracterização detalhada das propriedades mecânicas e elétricas dos protótipos, ao se considerar que a tensão de serviço para isoladores de baixa tensão é inferior a $1 \mathrm{kV}$, estes resultados sugerem que o material obtido a partir do resíduo tem grande potencialidade para esta aplicação.

\section{CONCLUSÕES}

O resíduo de esmaltação possui plasticidade suficiente para ser conformado por técnicas de moldagem plástica, exigindose, contudo, um estudo mais detalhado sobre o processo de secagem e a otimização da dosagem.

Ficou constatada a boa semelhança do resíduo com o material usado no isolador comercial, tanto em termos de composição química quanto mineralógica, observando-se basicamente os mesmos elementos químicos.

Quanto a capacidade de isolamento dos protótipos, os resultados de rigidez dielétrica extremamente elevados (maiores que $25 \mathrm{kV}$ ), juntamente com o fato da ruptura dielétrica não ter ocorrido através das amostras, sugerem que as formulações adotadas são compatíveis com o uso em isoladores elétricos de distribuição secundária.
Além de se esperar maiores valores de rigidez dielétrica com o ensaio de protótipos esmaltados, a ocorrência de ruptura dielétrica superficial indica uma tolerância diante das variações de composição apresentadas pelo resíduo de esmaltação a cada nova produção.

\section{AGRADECIMENTOS}

Os autores agradecem ao CNPq e à CAPES pelo suporte financeiro, à Eletrosul (Eng. Valci), pelos ensaios de ruptura dielétrica, e por fim ao Laboratório de Materiais do Departamento de Engenharia Mecânica da UFSC por toda estrutura disponibilizada.

\section{REFERÊNCIAS}

[1] F. G. Rosa, "Estudo da viabilidade de obtenção de placas cerâmicas para revestimentos a partir de resíduos sólidos industriais e minerais", Dissertação de Mestrado, Departamento de Engenharia Mecânica, Universidade Federal de Santa Catarina, Florianópolis, SC (2002).

[2] N. Yalçin, V. Seving, "Utilization of bauxite waste in ceramic glazes", Ceram. Int. 26 (2000) 485-493.

[3] P. Souza Santos, Ciência e tecnologia de argilas, 2a ed., Editora Edgard Blücher, S. Paulo (1989).

[4] W. Schmidt, Materiais elétricos, 2a ed., S. Paulo, Editora Edgard Blücher, v. 2: Isolantes e magnéticos (1979).

[5] D. B. Saraiva, Isolantes e dielétricos, in Materiais elétricos, Rio de Janeiro, Guanabara Koogan (1988) 98-107.

[6] Santa Catarina, Celesc, Isoladores de porcelana, $20 \mathrm{f}$, Manual especial, Cód. E-313.0011.

[7] A. KhalfI, P. Blanchart, "Desorption of water during the drying of clay minerals: enthalpy and entropy variation", Ceram. Int. 25 (1999) 409-414.

[8] F. J. P. Sousa, "Estudo e desenvolvimento de alternativas para o aproveitamento de resíduos das indústrias de revestimentos cerâmicos", Dissertação de Mestrado, Departamento de Engenharia Mecânica, Universidade Federal de Santa Catarina, Florianópolis, SC (2003).

[9] ABNT, NBR 13818 "Placas cerâmicas para revestimento Especificação e métodos de ensaios", Rio de Janeiro (1997). [10] F. H Norton, "Introdução à tecnologia cerâmica", S. Paulo, Editora Edgard Blücher (1973).

[11] M. A. A. Rossini,"Resistência à abrasão de vidrados utilizados para revestimento de pisos perâmicos", Dissertação de Mestrado, Departamento de Engenharia Mecânica, Universidade Federal de Santa Catarina, Florianópolis, SC (1992).

[12] L. H. Van Vlack, "Propriedades dos materiais cerâmicos", Editora Edgard Blücher, S. Paulo (1973).

(Rec. 15/12/03, Rev. 20/04/04, Ac. 14/05/04) 